\title{
Memória familiar e geográfica do químico Ferreira da Silva
}

\section{1 - Explicação}

Amabilidade grande, a do prof. Mário Berberan e Santos, Secretário-Geral da $S P Q$. A de me pedir a mim, um dos muitos descendentes do químico Ferreira da Silva (1853-1923, de quem em Julho deste ano se comemoram os 150 anos do nascimento) um artigo sobre o enquadramento familiar e geográfico deste patriarca da Química portuguesa.

\section{2 - Dificuldades}

Por um lado a minha qualidade de ex-advogado e de jornalista colaborador do Diário do Minho (no passado, também do Jornal de Notícias, do Porto) facilitam-me a expressão e o alinhamento de factos e ideias. Porém, quem quer que fale dos seus antepassados tem tendência a enaltecê-los. Mas quando o antepassado é Ferreira da Silva, um modelo de nós todos, será impossivel dizer mal. Por isso peço indulgência se alguma vez pisar o traço da imodéstia. De qualquer forma sei que vós, os cientistas, os químicos, os físicos, os farmacêuticos, não levareis a mal. Até porque Ferreira da Silva foi um grande homem apenas por ter sido um grande químico (exactamente como vós outros) e não por ter sido um "Ferreira da Silva" (exactamente como eu). E a vós todos dedico este frágil opúsculo. A vós, os cultores da ciência de "Quem", nada menos do que o nome do Antigo Egipto, onde fluía o poético Aur, que hoje se chama Nilo...

\section{3 - As biografias}

Este artigo não é uma biografia. As biografias e "curricula" daquele Mestre têm sido escritos por especialistas e uma das mais antigas será a do prof. ALBERTO DE AGUIAR. Penso até que o Boletim da SPQ publicará em 2003 uma delas, a propósito das comemorações. Este meu trabalho é apenas um enquadramento da pessoa de Ferreira da Silva na sua própria família e geografia pessoal. E inclui alguns "fait-divers" provavelmente mais relacionados com os seus parentes do que com ele próprio. Porque infelizmente já não se encontra vivo qualquer filho ou neto que com ele tenha convivido. 0 último, a sua filha Adozinda ( $n$. 1903) faleceu no início dos anos 90.

\section{4 - Breve História de Cucujães, onde nasceu}

A vila de Cucujães, (ou Couto de Cucujães) é muito antiga e situa-se no norte do distrito de Aveiro (lá onde os últimos contrafortes boscosos das serras da Beira Alta escorregam lentamente para o plácida Ria e vigiam o pouco distante Atlântico. 0 povoamento histórico mais antigo da região é celtibero (concretamente a tribo dos Túrdulos, que curiosamente tinha ligações ao Baixo Alentejo, onde viveu outro seu ramo). O principal burgo dos Túrdulos era Lancóbriga (hoje Fiães da Feira, 7 kms a norte). Estes lusitanos deram muito trabalho aos romanos, que conquistaram e povoaram a área no séc. II a.C. e seguintes. A zona de Cucujães, tal como Lancóbriga, ficava situada na via militar romana que ligava Lisboa e Santarém a Coimbra, ao Porto e a Braga. E daqui se deduzirá a mistura "racial" adveniente. Depois, com as invasōes germânicas, Cucujães foi incluída no reino suevo, cuja capital era Braga (e que durou até 585 d.C.). Os suevos deram lugar aos poderosos godos, que parecem ter deixado uma marca toponímica importante na zona de Cucujães - S. João da Madeira e que é o monte de Castro-Recarei, nome que é usualmente interpretado como o da elevação onde se situou um forte construído pelo rei visigodo Rekaredo. Com a conquista muçulmana (711-715) vieram povoadores árabes e sobretudo mouriscos. E tal como Rekaredo, também o célebre conquistador iemenita Al-Mansur ou "o vitorioso" (que destruiu Coimbra em 987 e Compostela em 997) deixou ficar o nome ligado à região, no caso à vizinha freguesia de Mansores (Arouca) e à aldeia de Almansor (Castelo de Paiva). Quando em 1086 o povoado primitivo de Cucujães (agora pertencente à Terra de Santa Maria) teve foral e couto, quem os deu foi ainda o rei de Leão, D. Afonso VI, avô de D. Afonso Henriques. Mas foi já no nosso $1 .^{\circ}$ reinado que se fundou o mosteiro de Cucujães, que haveria de durar até 1834 (e depois, de 1874 a 1910) mantendo-se a congregação até 1953 e sendo agora o Colégio das Missões. 0 nome de Cucujães, esse parece derivar do facto de ser terra onde cantavam muitos cucos (hoje raros) e a freguesia tem pertencido ao concelho de Oliveira de Azeméis, distrito de Aveiro.

\section{5 - 0 químico que nasceu num convento}

Ferreira da Silva nasceu curiosamente nesse convento de Cucujães, pois o seu pai era procurador das propriedades do mesmo, "nacionalizadas" pala reforma

\footnotetext{
* Bisneto do Prof. Ferreira da Silva, jornalista no "Diário do Minho"
} 

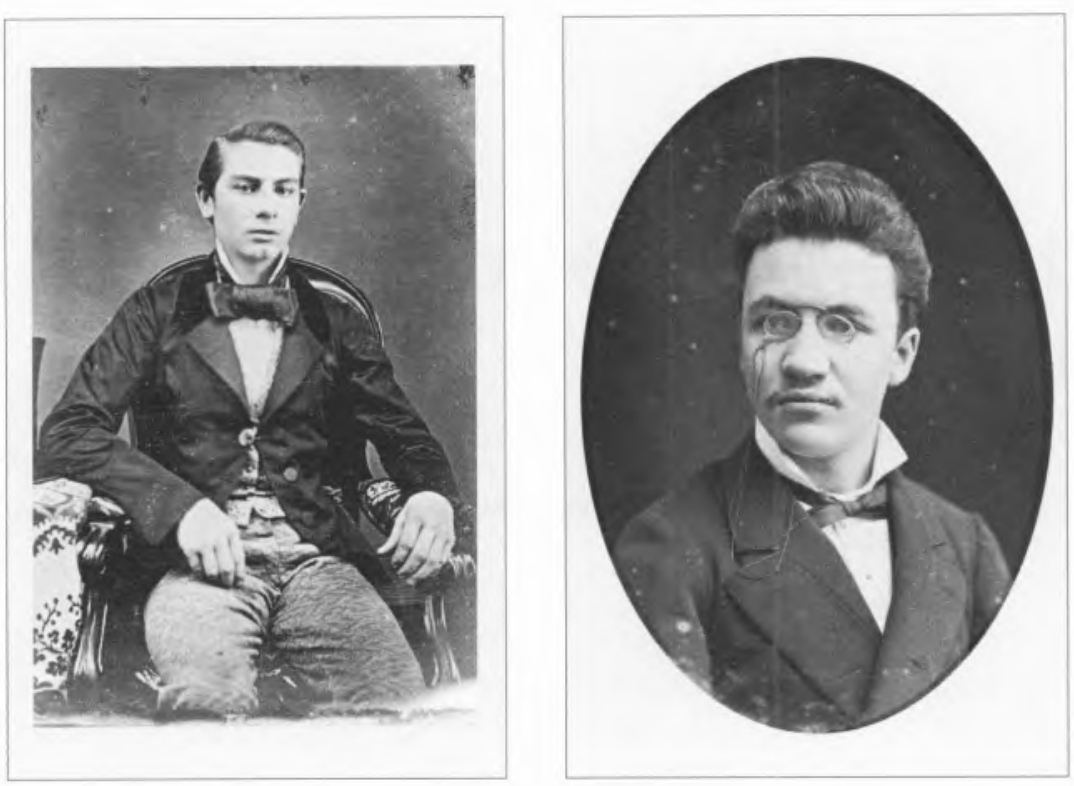

figura1 visconde de S. Tiago de Riba-Ul na adolescência; figura 2 quimico Ferreira da Silva aos 23 anos (26/05/1877);

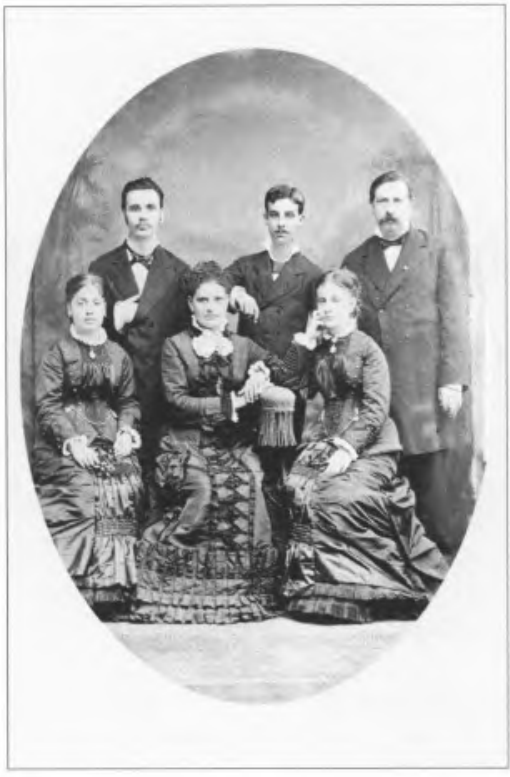

figura 3 o sogro visconde (em cima, à direita), com duas filhas (Beatriz, sentada à direita e Idalina, a futura esposa do químico, sentada à esq.), e alguns amigos no Rio de Janeiro, 09/03/1880; de Mouzinho da Silveira (1836). 02 2. $^{\circ}$ comprador da quinta do convento foi o capitalista luso-brasileiro Joaquim António F. da Silva, tio paterno do químico, homem que dividiu a sua vida entre o Porto e o Rio de Janeiro. A quinta pertenceu pois à família entre 1850 e 1868. Os restos mortais do ilustre químico repousam, aliás, no cemitério adjacente ao seu local de nascimento. "Mistérios" da Química Orgânica...

O lugar da sua morte foi contudo a casa do Lameiro, em Figueiredo, na vizinha Santiago de Riba-UI. E entre as muitas assinaturas de condolências, a de Salazar, então um desconhecido docente católico da Universidade de Coimbra. Registe-se ainda um telegrama de D. Manuel II, então no exílio.

\section{6 - Casado com uma prima brasileira}

Ainda não completara 27 anos e Ferreira da Silva já era, desde 20 de Maio de 1880, lente da Academia Politécnica do Porto, com regência de Química. Entre Agosto e Outubro de 1880, nesse ano de consagração, foi casar ao Rio de Janeiro com uma prima, Idalina de Sousa Godinho, filha do recém-criado Visconde de Santiago de Riba-UI, José Joaquim Godinho (1836-1885).

\section{7 - 0 sogro visconde}

Este seu sogro e primo era um grande comerciante e filantropo luso-brasileiro, ligado à fundação ou gestão de instituições cariocas tão notórias como a Beneficência Portuguesa, o Banco Rural e Hipotecário, o Liceu Português e o célebre Gabinete Português de Leitura, do qual era director interino no ano do seu prematuro falecimento, aos 48 anos de idade. Foi o rei D. Luis I que fez visconde este natural de Santiago de Riba-UI, freguesia vizinha de Cucujães.

0 casamento entre primos era relativamente vulgar no séc. XIX. A mãe do visconde, Ana Maria Joaquina, era irmã do pai de Ferreira da Silva, o acima referido (e homónimo) procurador dos bens do convento de Cucujāes, que viveu entre 1806 e 1869. E ambos eram irmãos do citado luso-brasileiro Joaquim António Ferreira da Silva (n. 1804) que comprou o convento de Cucujães (cf. N. ${ }^{\circ}$ ).

\section{8 - Séculos atrás}

Segundo as investigações, ainda incompletas, do genealogista e antiquário dr. MAURÍCIO ANTONINO FERNANDES, estes Silvas (que no início do séc. XVII já eram donos de terras na região de Cucujães e Santiago) viriam de Avanca, sendo pa- rentes remotos do prof. Egas Moniz. Ambas as famílias descenderiam dos Gomes da Silva, de S. Marcos, Coimbra.

\section{9 - A violenta memória de Napoleão}

Um dos mais vivos episódios históricos que perduram ainda na memória colectiva local da região de S. João da Madeira - Cucujães - Oliveira de Azeméis é o massacre de 300 civis inocentes que se tinham refugiado na igreja de Arrifana, tentando evitar a represália das tropas de Soult, em 1809, durante a 2. ${ }^{\mathrm{a}}$ invasão francesa. Essa represália fora originada pelo assassinato de dois oficiais franceses na vizinha Carcavelos (na ponte "dos cavaleiros"), por obra dos guerrilheiros locais, comandados por José Soares Barbosa da Cunha. Uma das vítimas fora o tenente-coronel Lameth, sobrinho do próprio Soult, que levava despachos para o gen. Franceschi, estacionado em Oliveira de Azeméis. Os comandantes do massacre da igreja de Arrifana foram os coronéis Zamiers e Olivete.

\section{0 - Um (bis)avô autarca}

Margarida Emília Ferreira (1828-1914), a mãe do químico, era filha ou neta (e desculpem a minha incerteza neste ponto) de Manuel Ferreira, por vários anos presidente do município de Cucu- 

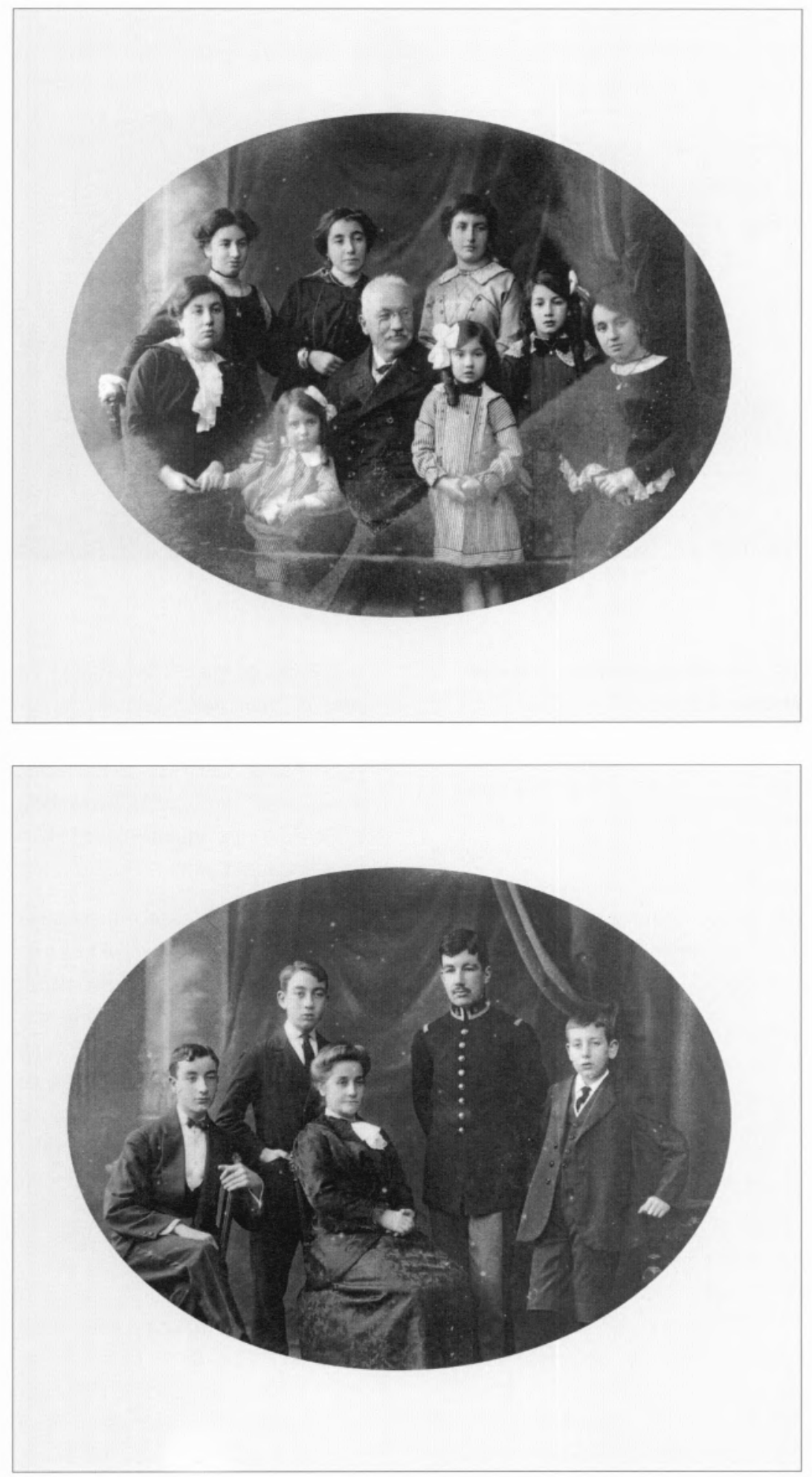

jães. Em fins de 1834, com a despromoção do concelho a simples freguesia, foi Manuel Ferreira também o seu $1 .^{\circ}$ presidente da junta. E ainda regedor, entre 1841 e 1844.

\section{1 - 0 actor Ferreira da Silva}

0 actor (Alfredo) Ferreira da Silva (1859-1923) que tem em Lisboa uma rua com o seu nome no Bairro dos Actores (junto à Av. Almirante Reis e à Alameda Afonso Henriques) e que foi casado com a não menos famosa actriz Virgínia (n. 1850) era parente do químico Ferreira da Silva. É que uma tia do actor (irmã do pai) era casada com um tio paterno do cientista, no caso Manuel

figura 4 Ferreira da Silva com as suas oito filhas;

figura 5 a esposa do químico Ferreira da Silva com os quatro filhos do casal (da esq. para a dir., José, Alberto, António e Alfredo);

José da Silva (n. 13-2-1802 em Santiago de Riba-Ul, Oliveira de Azeméis).

$\mathrm{O}$ actor deixou descendência em Lisboa através dos vários netos que lhe deu sua filha Maria Ema Campos. Por outro lado, o actor era também primo do escultor Thomaz Costa (1861-1932), autor das estátuas do marquês Saldanha (Lisboa), 
figura 6 casa da Manta, em Cucujães (Oliveira de Azeméis), dos antepassados maternos de Ferreira da Silva;

infante D. Henrique (Porto) e António Nobre (Coimbra).

\section{2 - 0 parentesco com o matemético Ruy Luís Gomes}

$\mathrm{O}$ antigo candidato à presidência da República (em 1958) e um dos maiores matemáticos portugueses, Ruy Luís Gomes (1905-84) era parente consanguíneo do químico Ferreira da Silva. É que o químico era $2 .^{\circ}$ primo do pai deste célebre matemático (Professor nas universidades do Porto, Recife e Mar del Plata). Este pai de Ruy Luís Gomes foi o não menos célebre António Luís Gomes (1863-1961) ministro da Justiça do $1 .{ }^{\circ}$ Governo Provisório da República Portuguesa (1910), reitor da Universidade de Coimbra e embaixador no Brasil. Os Ferreira da Silva e os Luis Gomes têm bisavós comuns em Santiago de Riba-UI (Oliveira de Azeméis) na chamada Casa do Salgueiro e na pessoa do casal Ana (n. 1736) e Manuel José da Silva (n. 1741), que por acaso são antepassados de mim próprio por quatro lados diferentes...

Um irmão de Ruy Luís Gomes foi o dr. António Luís Gomes (n. 1898), administrador dos bens da casa de Bragança, director da Fazenda Pública entre 1933 e 40 e governador do Banco de Portugal, salvo erro nos anos 60 .

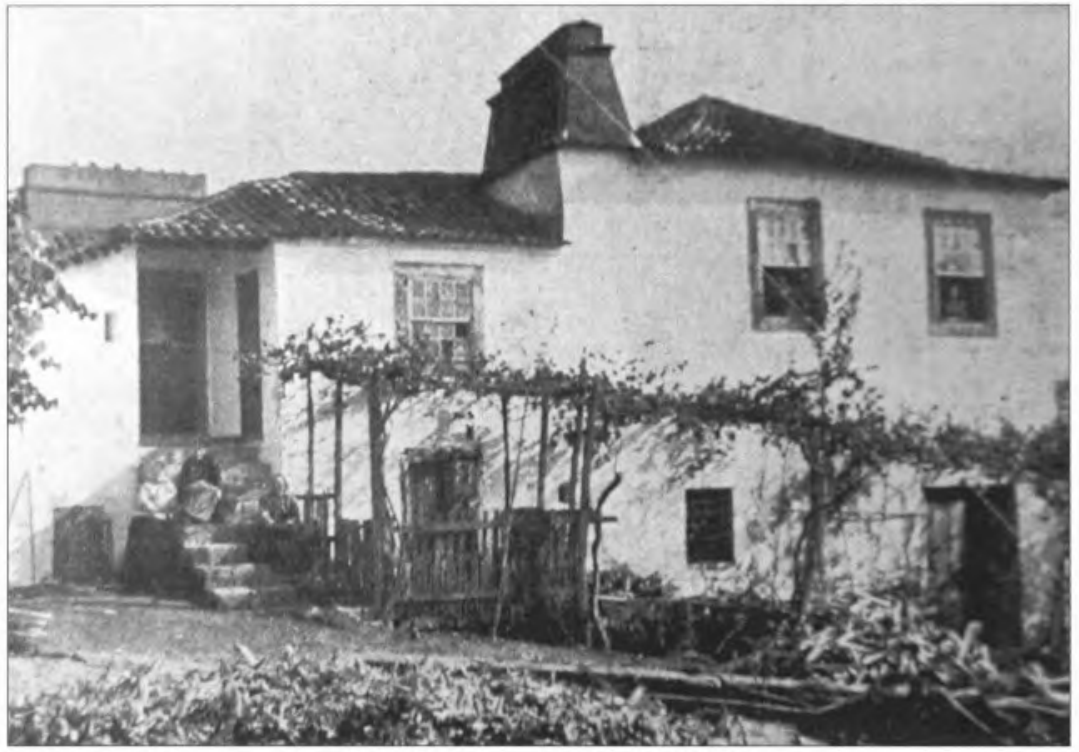

\section{3 - Com Brito Camacho, o Padre Américo e outros}

Ferreira da Silva, apesar de todo o saber adquirido (ou por via dele mesmo...) manteve-se ao longo da vida católico e monárquico, nunca renegando o regime que o cumulara de honrarias (desde o Pariato ao Conselho de Sua Majestade ou à Comenda de Nossa Senhora da Conceição).

Entre os muitos alunos de que foi professor conta-se o notável político republicano conservador Brito Camacho (1862-1934), chefe histórico da "3. força", o partido Unionista. Natural de Aljustrel, militar, médico, escritor e jornalista, Brito Camacho foi ministro do Fomento no $1 .^{\circ}$ governo republicano e governador de Moçambique em 1921-22. Nessa qualidade visitou Brito Camacho as minas de carvão de Tete, das quais era à época, jovem director o meu avô António (engenheiro militar e filho mais velho do químico). Este encontro inesperado narra-o Brito Camacho no seu livro "Terra de Lendas" (página 242 da $1 .^{\text {a }}$ edição). E recorda a propósito, como o químico Ferreira da Silva o salvara de um imerecido chumbo num exame da Academia Polytechnica do Porto. Gentileza que Brito Camacho retribuiu quando o meu bisavô Ferreira da Silva o visitou, agora ministro, em Lisboa (por 1911) para the falar de um qualquer outro assunto (ibid., "Terra de Lendas").
Com o Padre Américo (1887-1956) há a história de, num certo sarau de caridade ocorrido no Porto, o benemérito e temperamental sacerdote ter recusado a oferta deste meu citado avô militar "porque ele e o pai (químico) e a família já haviam dado de sobra".

Ferreira da Silva foi também bastante amigo do famoso missionário e bispo do Porto, D. António Barroso (1854-1923), homem que, tal como o Padre Américo, também deixou rasto de santidade entre o povo nortenho. E quando a mãe de Ferreira da Silva morreu (Fevereiro de 1914) foi na terra natal do bispo (RemeIhe, em Barcelos) mandada celebrar uma missa; e o facto vem noticiado, com fotografia, na Ilustração Católica, importante revista da época.

Com Bento Carqueja, largos anos director e proprietário do O Comércio do Porto, a amizade e protecção dispensada pelo químico eram notórias, inclusive no próprio meio académico. Diziam as "más línguas" (em sentido próprio, provavelmente...) que tinha sido a amizade com Ferreira da Silva que fizera de Carqueja professor universitário.

\section{4 - Teve 14 filhos, dos quais 5 deixaram vasta descendência}

Assim foi, como era costume naqueles tempos. Dois desses filhos morreram na infância. Os restantes, foram 8 raparigas e 4 rapazes. Entre a filha mais velha, Alexandrina (nascida no Rio de Janeiro 


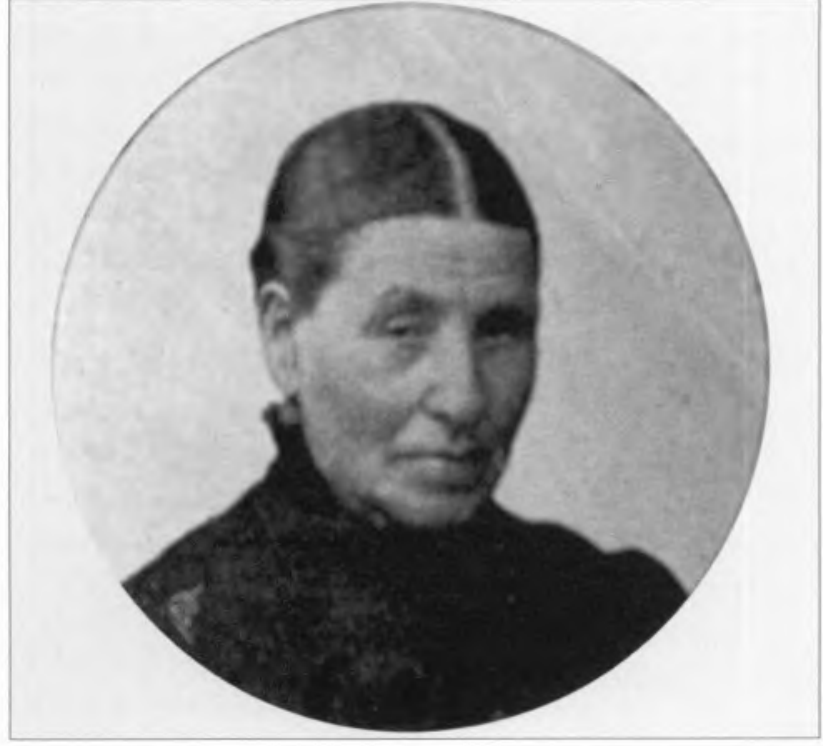

figura 7 Margarida Emília Ferreira da Silva, mãe do químico, falecida em 1914 aos 86 anos de idade; em 1883) e a mais nova, Margarida (nascida no Porto em 1909) havia mais de 26 anos de diferença. As outras fiIhas foram Alzira, Idalina (1889-1973, professora de música do Conservatório do Porto), Alice (casada com um professor francês, Mathieu Valadier, 1883-1957), Adelina, Adozinda, Antónia (casada com o médico portuense José Pereira Fernandes e mãe do prof. José António F. S. Fernandes, da Faculdade de Medicina da Universidade do Porto) e ainda Margarida (professora liceal de Letras que leccionou na antiga Lourenço Marques onde teve Otelo como aluno; e que foi casada com um seu colega de Viseu, o dr. António Pais da Cunha Jardim, pais do engenheiro António Jardim, outrora investigador no campo da energia atómica e depois ligado ao porto de Sines e à câmara de Setúbal).

\section{5 - António, o filho mais velho, com Salazar e Gomes da Costa}

Aqui, estou a falar do meu avô paterno, António Joaquim Ferreira da Silva Júnior (1887-1947) tenente-coronel de engenharia, o tal que vem referido acima, no n. ${ }^{\circ} 12$, e que Brito Camacho encontrou nas minas de Tete. Foi engenheiro-militar pela Escola do Exército e tinha também os cursos de Engenharia Civil, de Minas e de Electricidade. Foi o $2 .^{\circ}$ aluno do curso, atrás apenas do político Cunha Leal (1888-1970) que Ihe era superior em esgrima e equitação. Fez, como jovem capitão, a Guerra de 1914-18 na Flandres, no quartel general do irascível general Gomes da Costa (1863-1931) mais tarde presidente da República (logo depois do movimento do 28 de Maio de 1926, em que este mesmo meu avô também participou). Uma vez, nas trincheiras, o general perdeu a calma porque nenhum telefone funcionava. Logo chamou o meu avô, que rapidamente solucionou a "falha técnica", por acaso imputável ao próprio general... 0 Capitão António Ferreira da Silva esteve aliás na retaguarda da célebre batalha de La Lys (1918) como radio-telegrafista.

Nos anos 20 encontramo-lo na prospecção mineira da Zambézia e Tete. Volta então ao Porto onde é comandante do Batalhão de Telegrafistas. Nos anos 30 é membro do governo de Macau (director das Obras Públicas e Encarregado do Governo). Já major, foi director das Obras Militares da II Região Militar (Coimbra) e depois, comandante do Batalhão de Pontoneiros, em Tancos.

Quando nos anos 40 Salazar visitou o castelo de Almourol e aí jantou, foi ele que organizou o pontão com barcaças que permitia o acesso à ilha. Há até desta visita, uma anedota verídica, demonstrativa dos traços de carácter que este meu avô herdara de seu pai, o químico Ferreira da Silva. Salazar interrogou, sucessivamente e por ordem hierárquica, as altas patentes militares presentes acerca do funcionamento de um grande frigoríico a petróleo que se encontrava nas imediações. E sucessivamente os generais iam dando explicações vagas e fluidas, nenhum deles confessando a sua ignorância. "E então - Sr. Major Ferreira da Silva, será que me poderá explicar melhor este funcionamento?" perguntou Salazar. Logo o meu avô se levantou da mesa e batendo continência retorquiu ironica, cientifica e teatralmente: "Senhor Presidente do Conselho, eu também não sei!". Salazar não levou a mal...

O seu último cargo foi, durante a $2 .^{a}$ Guerra Mundial, o de comandante da Engenharia do Exército, nos Açores.

Casara aos 37 anos com Maria Luísa, uma sua parente, sobrinha-neta do pai do actor Ferreira da Silva. 0 único filho do casal foi meu pai, António C. A. Ferreira da Silva (1926-84), largos anos assistente e professor de Matemática na Universidade do Porto e desde 1977 na de Aveiro.

\section{6 - José, o $2 .^{\circ}$ filho de Ferreira da Silva}

Este José (1895-1953) tinha também vários cursos e altas classificações. Licenciado em Fisico-Químicas e depois em Engenharia Civil, chegou a dar aulas nesta Faculdade no Porto. Concluiria ainda os estudos, na Escola do Exército, para a arma de Infantaria. Esteve em França na $1 .^{\text {a }}$ Grande Guerra, donde regressou com a saúde algo debilitada, o 
que não o impediu de ser toda a vida um trabalhador incansável. Engenheiro e professor (também no liceu), logo se ligou à indústria cerâmica, chegando a director da Empresa Cerâmica do Fojo (no norte) e mais tarde director da Fábrica de Louça de Sacavém.

Foi, além disso, presidente do Grémio dos Industriais de Cerâmica e procurador à Câmara Corporativa, além de membro do Conselho Superior dos Transportes Terrestres e do Fundo Especial dos Caminhos de Ferro. Foi casado com Maria Emilia Saraiva de Aguiar, uma senhora de origem vila-realense, parente do actual chefe do governo, Durẫo Barroso, pelo lado dos Saraivas.

Dos cinco filhos do engenheiro José, um foi o arquitecto José Guilherme Ferreira da Silva (1929-95), que concebeu o aldeamento de Vale de Lobo, no Algarve.

\section{7 - Alberto, o $3 .^{\circ}$ filho; a ordem de Cristo e Nemésio}

Este Alberto (1898-1978) foi engenheiro agrónomo aos 21 anos. Logo professor da Escola Nacional de Agricultura, em Coimbra, da qual seria por vários anos director. Sócio do Instituto de Coimbra, foi por dois anos Governador Civil do mesmo distrito de Coimbra. Em 1942 foi para Angola instalar a Escola Agro-Pecuária da Huila, em Tchivinguiro. Nesse distrito da Huíla foi também Encarregado do Governo. Regressou a Lisboa para trabalhar na Direcção Geral do Fomento (Min. do Ultramar). Foi então eleito para o Bureau International des Soles, o que o levou a viver quase dois anos em Paris. Terminou a carreira como director-adjunto do Instituto do Vinho do Porto, até se reformar em 1968.

Foi condecorado com a comenda da Ordem de Cristo portuguesa e com a da Ordem do Leão (belga), pelos seus trabalhos em África. Casou com Maria Luísa de Canaes e Mariz, dona que foi da quinta da Bencanta, em Coimbra. Esta senhora é mencionada na biografia de Salazar (de FRANCO NOGUEIRA, vol. I, páginas 100-101) como uma jovem pianista que animou saraus que o estudante Salazar frequentava, nomeadamente o de 2-2-1913. Consta até que Salazar chegou a andar pela Bencanta, mas mais "curioso" acerca duma irmã desta Maria Luísa, que dela própria...

Uma das filhas do engenheiro Alberto Ferreira da Silva (também chamada Maria Luísa) casou com o dr. Jorge Nemésio, antigo cônsul de Portugal em Tours e Barcelona, filho que foi do escritor Vitorino Nemésio. Outro filho do eng. ${ }^{\circ}$ Alberto foi o engenheiro-silvicultor Luis Ferreira da Silva (n. 1926), o qual, depois de trabalhar para o governo português quase uma década, na Zambézia, fez carreira como funcionário da ONU (FAO) sucessivamente no Panamá, Colômbia e Nicarágua. Uma filha sua, também engenheira agrónoma, está casada em Santarém com um colega, Vasco Sá Nogueira, um 5. ${ }^{\circ}$ neto do marquês de Sá da Bandeira, tendo 3 filhos. Por este casamento tornou-se também afim do prof. Hermano Saraiva, que é casado com uma senhora Sá Nogueira.

\section{8 - A "Legião de Honra" do 4. ${ }^{\circ}$ filho, Alfredo, cunhado de Fernando Pessa}

Com os olhos azuis, o nariz grosso como o pai e aspecto jovial, o comandante Alfredo Ferreira da Silva (1901-73) era o mais novo e seguramente o mais extrovertido dos quarto irmãos. Ainda nos preparatórios da Escola Naval, participou no movimento da chamada Monarquia do Norte, desse herói de África que foi Paiva Couceiro (1919). Parece que regressou a pé até ao Porto desde o norte de Trás-os-Montes, muito bem acolhido pelos sacerdotes e populares de várias aldeias do Marão. Tornou-se oficial de Marinha Piloto-aviador, começando pelas bases de S. Jacinto (Aveiro) e Bom Sucesso (Lisboa). Chegou durante alguns anos a ser director da Aeronáutica Naval. Ainda antes da 2. ${ }^{\text {a Guer- }}$ ra Mundial fizera, em aviões primitivos, muitos voos para a Madeira e Açores. Durante esse mesmo conflito, comandou a canhoneira Diu na fiscalização da costa portuguesa; e outros navios de guerra com base na Madeira, Cabo Verde e Guiné, salvando inúmeros náufragos, vítimas das hostilidades. O seu último comando foi o navio Afonso de Albuquerque na antiga Índia Portuguesa, reformando-se em 1959 como capitão de mar-e-guerra.
Como aviador militar caiu duas vezes (em Angeja e no Tejo); participou também no Golfo de Biscaia nas buscas do avião de Ramón Franco (o irmẫo do "caudilho"). E viajou várias vezes ao estrangeiro em comissões de serviço para a compra de material aeronáutico.

Foi condecorado pela França (tal como o químico seu pai) com a Legião de Honra; pela Inglaterra, com a medalha de Victória; e pela Espanha e Brasil, com as respectivas comendas de Mérito Naval.

Teve um casamento longo e feliz com D. Palmira Pessa, a única irmã do conhecido locutor Fernando Pessa. Sobre a competência, honestidade e capacidades do Comandante Alfredo Ferreira da Silva, poderá indagar-se junto do almirante Fuzeta da Ponte, que o conheceu bem de perto.

\section{9 - Uma rua em Lisboa?}

António Joaquim Ferreira da Silva, patriarca da Química lusa, é homenageado em várias localidades que deram o seu nome a ruas, ou the erigiram bustos.

Nomeadamente no Porto, onde há uma rua no centro da cidade com o seu nome; além de um baixo-relevo na parede exterior do Instituto de Medicina Legal (em frente ao Hospital de St. António) e um busto no interior da Faculdade de Ciências. No lugar em que nasceu, Cucujães, há outro busto, numa praceta.

Cairia mal que, nos 150 anos do seu nascimento, seja em Lisboa dado o nome do Químico Ferreira da Silva, a uma praça ou a uma rua?

Um país fica sempre maior ao homenagear os seus maiores.

Agradecimentos por contribuições para este trabalho a:

Eng. Luís Alberto C.M. Ferreira da Silva Dr. Maurício Antonino Fernandes

Dr. ${ }^{a}$ Maria Helena Barbosa

Dr. Gonçalo Nemésio

Porto, 27 de Junho de 2003 